\title{
Electrical Dielectric Authorship of Polyvinyl-Acetate and Toluene Diisocyanate (PVA-TDI) with Manufactured Sulfonated Phenol-formaldehyde (SPF) Viscous Mass Material Composite
}

\author{
Assist. Prof. Thamir Salman Bachari
}

Polymer Research Centre-Material Science Department, University of Basrah, Iraq.

\author{
Received 7/3/2016
}

Accepted 27/10/2016

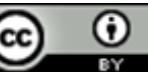

This work is licensed under a Creative Commons Attribution 4.0 International License

\begin{abstract}
:
The electrical insulation of the manufacture sulfonated phenol-formaldehyde viscous material (product) has been studied with Polyvinyl-acetate (PVA) and toluene diisocyanate (TDI) blend has been prepared by fixing percentage by weight $3: 1$ and mixed with different percentages by weight of the product sulfonated phenol formaldehyde viscous mass (SPF). The Fourier transform infrared (FTIR) spectroscopy is done on (SPF) resin powder and prepared film of PVA-TDI-SPF viscous mass. The quality factor $(\mathrm{Q})$, dissipation factor $(D)$, parallel resistance $\left(R_{p}\right)$, series resistance $\left(R_{s}\right)$, parallel capacitance $\left(C_{p}\right)$, series capacitance $\left(C_{s}\right)$ and phase shift $(\phi)$ are measured. The calculated maximum dielectric constant $\left(\varepsilon^{\prime}\right)$ is $3.49 \times 10^{7}$ at sample (1) wt.1\% SPF viscous mass to the weight of (PVA-TDI), the minimum dielectric constant is $1.12 \times 10^{6}$ at sample (3) wt.3\% of SPF viscous mass to PVA-TDI weight. The maximum dielectric loss factor $\left(\varepsilon^{\prime \prime}\right)$ is $3.68 \times 10^{7}$ at sample $(1)$ and the minimum dielectric loss is $2.04 \times 10^{6}$ for sample (3). The maximum conductance is $1.06 \times 10^{-4} \mathrm{~S}$ at sample (1) and minimum conductance is $6.64 \times 10^{-6}$ at sample (3). The maximum frequency dependent ac. conductivity $\left(\sigma_{\mathrm{ac}}\right)$ is $2.048 \mathrm{~S} \mathrm{~m}^{-1}$ for sample (1) and the minimum is $0.113 \mathrm{~S} \mathrm{~m}^{-1}$ at sample (3). The maximum total conductivity $\left(\sigma_{t}\right)$ is 126.2 $\mathrm{S} \mathrm{m}^{-1}$ for sample (1) and minimum $\left(\sigma_{t}\right)$ is $1.129 \mathrm{~S} \mathrm{~m}^{-1}$ for sample (3). The maximum independent conductivity $\left(\sigma_{\mathrm{dc}}\right)$ is $124 \mathrm{~S} \mathrm{~m}^{-1}$ for sample (1) and minimum value is $1.015 \mathrm{~S} \mathrm{~m}^{-1}$ for sample (3). The maximum capacitive reactance $\left(\mathrm{X}_{\mathrm{s}}\right)$ is 0.83 $\mathrm{M} \Omega$ at sample (5) wt.5\% SPF viscous mass to PVA-TDI weight and the minimum is $0.14 \mathrm{M} \Omega$ for sample (3).
\end{abstract}

Key words: Mixture, Electrical Insulators, Conductivity, Capacitive Reactance.

\section{Introduction:}

Dielectrics are class of materials that are highly resistive to electrical current. A few simplified definitions of dielectric own qualities are important for the meaningful discussion of their measurements and applications. They

have been defined previously in terms of electrical circuit concepts and electromagnetic field concepts. Permittivity $(\varepsilon)$ can be represented by a complex quantity relative to the permittivity of free space $\varepsilon_{0}$. The real 
part $\varepsilon^{\prime}$ is the dielectric constant that is a direct measure of amount of energy can be stored in a material in the form of electric field in the material. The imaginary part $\varepsilon^{\prime \prime}$ is the loss factor that is associated with ability of the material to absorb or dissipate energy that converts electric energy into heat energy[1]. The distinct qualities of polymers depend upon several factors like molecular weight, chemical nature of the units composing the polymer and morphology in solid state. Generally the dielectric characterization of polymers is studied as a function of the degree of polymerization, frequency, temperature and pressure[2]. The physical structure of polymer composites in the solid or viscoelectric state is of great importance in determining the dielectric behavior. The dielectric own quality of polymer composite materials have been studied with a view to modify the own quality of polymer system for practical applications. The inorganic insulators and dielectrics have been largely replaced by polymers on account of their quality and ability for specific needs. Epoxides, and polyesters have been used in electronics as insulators, dielectrics substrates, potting compounds[3]. In order to present unambiguous picture of the dielectric behavior of a such a system, a careful analysis and evaluation of the two major dielectric parameters namely dielectric constant (representing polarization) and tangent of dielectric loss angle (representing relaxation phenomena) is desirable [4]. A material is classified as "dielectric" if it has the ability to store energy when an external electric field is applied. It is well known that composites can be produced exhibiting enhanced behaviors that the constituent materials may not exhibit. For instance, from the combination of different fibers or fillers with polymer matrices one can produce polymer-matrix composites, a material important to the electronic industry for its dielectric nature in the use of capacitors[5]. Phenol formaldehyde (PF) adhesive is widely utilized in various industrial fields for its advantages such as high bonding strength, good chemical stability and resistance of water, heat and wear. With the development of economy, further improvement of its quality and performance is required. Therefore many researchers have carried out the modifications of $\mathrm{PF}$ with different methods[6]. Fourier transform infrared spectrometry (FTIR) spectroscopy has been employed widely to examine microscopic areas in polymers for the last twenty years. The technique has attained high precision and accuracy in measurements in researches and development purposes[7]. FTIR spectroscopy could be a possible option is used to obtain functional group information of SPF and functional group of PVA-TDI-SPF. The investigation represents the dielectric measurement carried out on PVA-TDI-SPF mixture at frequency $1 \mathrm{kHz}$, and laboratory temperature, and to rationalize the dielectric own quality of PVA-TDI-SPF. The effect of different percentage by weight of SPF viscous mass on the electrical dielectric of PVA-TDI gives a significant results of Gs, $\varepsilon^{\prime}, \varepsilon^{\prime \prime}, \sigma_{\mathrm{ac}}, \sigma_{\mathrm{dc}}$, $\sigma_{\mathrm{t}}$ and capacitive reactance.

\section{Materials and Methods:}

A-Manufacture of Sulfonated Phenol-Formaldehyde Resin (SPF) 42.5 moles of phenol, Thomas Baker, India, has been put in a clean bottom round flask $500 \mathrm{ml}$. in capacity and emplaced in Isomental heater sort LabHeat BAECO, Germany. A stop-fit thermometer and a condenser are connected at both sides of the bottom round flask, and stirrer sort Heidolph, Germany, are used with rubber to close the middle of the bottom round flask and operating the system. Set up of the system is shown in Figure (1). The 
system is operated and the phenol is heated to appropriate temperature and mixing to dissolve any solid bodies. The system is stopped and 4 moles of sulfuric acid $97 \%$ in concentration Thomas Baker India, are added slowly to the dissolved phenol, from the stop-fit thermometer side by using pipettes and the bottom round flask is closed again, the system is operated, the stirrer adjusted to an appropriate speed on scaling 2 measure 6 (800 $1 /$ min.rpm) and the temperature is raised, and maintained between $100-120{ }^{\circ} \mathrm{C}$ and the reflux has been done for two hours. The system is stopped and the temperature is left to cool slowly, then the bottom round flask is emplaced in an ice path and 12 moles of Formaldehyde, Thomas Baker, India; has been added by using pipettes, a fizzing and bubbling is occurred, the temperature is raised and stirred by hand using clean glass then the temperature is cooled to $35^{\circ} \mathrm{C}$ then below $22{ }^{\circ} \mathrm{C}$. Continuous stirring is done until a viscose solid mass is obtained; the product is left over night. The $\mathrm{PH}$ is examined by using indicator paper which is colored red, low $\mathrm{PH}$. $\mathrm{NaOH}$ solution has been prepared in a separate flask and drops are added until over saturation is reached by the high $\mathrm{PH}$, a few drops of $\mathrm{H}_{2} \mathrm{SO}_{4}$ have been added for equilibrium until $\mathrm{PH}=7$ is reached. The solution has been removed into clean plastic container this is a viscous mass of SPF and the precipitate (SPF) resin is put in a glass plate to be dried at room temperature that is collected in plastic container.

\section{B-Fourier Transform Infrared (FTIR) Spectroscopy:}

FTIR Spectroscopy of Sulfonated Phenol-Formaldehyde resin (SPF):

A sample of manufactured sulfonated phenol-formaldehyde resin, is crushed by stainless steel mortar, is examined with $\mathrm{kBr}$ disc by Fourier transform Infrared (FTIR) JASCO FTIR 4200 spectrophotometer serial No. C081761018, Japan as in Figure (2). The peaks at $1128.39 \mathrm{~cm}^{-1}$ and $1175 \mathrm{~cm}^{-1}$ correspond to C-C-O asymmetric stretch and $\mathrm{C}-\mathrm{H}$ in plane formulation respectively while the $1000 \mathrm{~cm}^{-1}$ and $748.8 \mathrm{~cm}^{-1}$ peak belong to the $\mathrm{C}-\mathrm{H}$ out of plane vibration. The peak at 1506.37 $\mathrm{cm}^{-1}$ correspond to the $\mathrm{C}=\mathrm{C}$ aromatic ring vibration. The above mentioned peaks diminish with increasing reaction time while the absorbance band of hydroxyl groups increase. Peak at $1034.14 \mathrm{~cm}^{-1}$ is the stretching vibration of $\mathrm{C}-\mathrm{O}[8]$ and band at $3503.3 \mathrm{~cm}^{-1}$ is stretching vibrations of $\mathrm{OH}$, Guo, et al[6]. Table (1) indicates the comparison between the obtained results with previous study.

\section{FTIR Spectroscopy of PVA-TDI-SPF:}

A sample of polyvinyl acetate with Toluene diisocyanate is blended by percentages $3: 1$ by weight and mixed with wt.1\% of the manufactured sulfonated phenol-formaldehyde viscous mass is prepared on clean glass substrate and left to dry in room temperature for two weeks. The sample is crushed by ceramic mortar and examined with $\mathrm{kBr}$ by Fourier Transform Infrared Instrument JASCO FTIR 4200 spectrophotometer serial No. C081761018, Japan as in Figure (3). The spectra are taken from 400 to 4000 $\mathrm{cm}^{-1}$. The peak at $843.222 \mathrm{~cm}^{-1}$ and wave number $946.395 \mathrm{~cm}^{-1}$ is $\mathrm{C}-\mathrm{H}$ out of plane phenol. The wave number at $1116.1 \mathrm{~cm}^{-1}$ is $\mathrm{C}-\mathrm{H}$ in plane. The wave number at $1252.06 \mathrm{~cm}^{-1}$ is $\mathrm{C}-\mathrm{C}-\mathrm{O}$ phenol, Poljansek, [8]. The band at $3308.29 \mathrm{~cm}^{-1}$ is the hydroxyl group[9]. Band at $1739.48 \mathrm{~cm}^{-1}$ is assigned to free carbonyl, while a lower frequency at $1651.73 \mathrm{~cm}^{-1}[10]$. 


\section{C- Samples Preparation}

Glass substrates are cleaned by rinsing for several times with distilled water then by acetone until they dried, again with distilled water for several times. The glass substrates are dried in furnace under vacuum for one hour. Percentage 3:1 of PVA: TDI by weight is prepared using sensitive electric balance sort Sartorius, Germany and blended on the clean glass substrates. The prepared sulfonated phenolformaldehyde (SPF) viscous mass is added in percentages by weight (wt.1\%, wt. $2 \%$, wt. $3 \%$, wt. $4 \%$ and wt. $5 \%$ ) to the blend and the compound is mixed by hand using thin glass rod and spatula until homogeneous mixtures are obtained and to ensure uniform thicknesses. Two copper wires are connected at both ends of bulk samples, which are left to dry overnight. The thickness and electrode diameters of the samples are measured using Vernier Certificate made in China, as shown in Table (3). The samples undergo dielectric measurement.

\section{D-Dielectric Measurement}

Dielectric measurements have been done by using LCR meter; sort FLUKE RCL Meter, Automatic 6303 MP, No. Lo 781003, Germany. The measurements include the electric parameter, the quality factor (Q), dissipation factor (D), impedance (Z), (Rp), (Rs), (Cp), (Cs) and ( $\phi)$. The calculations of dielectric constant $(\dot{\varepsilon})$, dielectric loss $(\check{\varepsilon})$ ac conductivity $\left(\sigma_{\mathrm{ac}}\right)$ and dc conductivity $\left(\sigma_{\mathrm{dc}}\right)$ have been calculated from the formulae below, Table (4) shows the measurements and calculated values. The dielectric constant $(\dot{\varepsilon})$ and dielectric loss $(\tilde{\varepsilon})$ of samples are calculated using the following relations. The dielectric constant is given by the relation [11]:

$$
\varepsilon^{\prime}=\frac{\text { Cs d }}{\varepsilon 0 \mathrm{~A}}
$$

Where $C_{s}$ the series capacitance, $\varepsilon_{0}$ is the permittivity of free space and equal to $8.83 \times 10^{-12} \mathrm{~F}$ and $\mathrm{d}$ is the sample thickness in $\mathrm{m}$. The dielectric loss is given by $\quad \varepsilon^{\prime \prime}=\frac{\varepsilon^{\prime}}{\mathrm{Rp} \mathrm{Cp} \mathrm{W}}$

Where $\mathrm{Rp}$ is the parallel resistance in $M \Omega, C_{p}$ is the parallel capacitance in Pf and $\mathrm{W}$ is the angular frequency is equal to $2 \pi \mathrm{f}$, where $\mathrm{f}$ is the frequency in Hertz. The capacitance of free space $\mathrm{C}_{0}$ is given by the equation

Co $=\frac{\varepsilon o \mathrm{~A}}{\mathrm{~d}}$...(3)

Where the dimensions have been measured by micrometer, the diameter of the electrode is $0.07 \times 10^{-3} \mathrm{~m}, \mathrm{~A}=\frac{\pi D^{2}}{4}$ is the area of the electrode is equal to $3.846 \times 10^{-9} \mathrm{~m}^{2}$. and $\mathrm{d}$ is the thickness of the electrode $0.07 \times 10^{-3} \mathrm{~m}$. the calculated Co is equal to $4.863 \times 10^{-4} \mathrm{pF}$

The frequency dependent conductivity can be calculated by the formula[12]:

$$
\sigma_{\mathfrak{a c}}=\varepsilon^{\prime \prime} \varepsilon \mathrm{ow} \ldots
$$

The conductance is given by the formula:

$$
\mathrm{Gs}=\varepsilon_{\mathrm{o}} \mathrm{C}_{\mathrm{o}} \mathrm{W}
$$

The total conductivity is given by the formula;

$$
\sigma=\mathrm{Gs} \frac{\mathrm{d}}{\mathrm{A}} \ldots(6)
$$

The total conductivity is also given by the relation:

$$
\sigma_{\mathrm{t}}=\sigma_{\mathrm{ac}}+\sigma_{\mathrm{dc}} \ldots(7)
$$

Where $\sigma_{\mathrm{dc}}$ is independent frequency $\mathrm{dc}$ conductivity

The complex impedance $\mathrm{Z}$ is given by the relation:

$$
Z=R s+X s
$$

Where Rs is the equivalent series resistance and $\mathrm{Xs}$ is the capacitive reactance is given by

$$
\mathrm{Xs}=\frac{1}{2 \pi \mathrm{fCs}}
$$




\section{Results and Discussion:}

Table 1 Comparison between the Obtained Results with Previous Study of SPF Resin

\begin{tabular}{|c|c|c|c|c|}
\hline $\begin{array}{c}\text { Literature Data } \\
\mathrm{cm}^{-1} \text { Ref. No.5 }\end{array}$ & $\begin{array}{c}\text { Functional } \\
\text { Group Obtained }\end{array}$ & $\begin{array}{c}\text { Wave number } \\
\mathrm{cm}^{-1}\end{array}$ & $\begin{array}{c}\text { Functional Group. } \\
\text { Ref. }\end{array}$ & $\begin{array}{c}\text { Observed } \\
\mathrm{cm}^{-1}\end{array}$ \\
\hline 1240 & C-C-O & 1200 & C-C-O phenol & 1224 and 1262 \\
\hline 1180 & $\begin{array}{c}\text { C-H } \\
\text { in plane }\end{array}$ & 1175 & $\begin{array}{c}\text { C-H aromatic } \\
\text { phenol }\end{array}$ & 1170 \\
\hline 835 & $\begin{array}{c}\text { C-H out of } \\
\text { plane phenol }\end{array}$ & 1000 and 748.8 & $\begin{array}{c}\text { C-H out of plane, } \\
\text { para }\end{array}$ & 826 \\
\hline 760 & & 750 & $\begin{array}{c}\text { C-H out of plane, } \\
\text { ortho }\end{array}$ & 756.6 \\
\hline 1153 & C-O & 1034.14 & C-O stretch & 1154 and \\
\hline---------- & C-H unsaturated & 3024.43 & $\begin{array}{c}\text { C-H unsaturated } \\
\text { stretched phenol }\end{array}$ & 3026 \\
\hline 1610 and 1517 & C=C & 1506.37 & C=C & 1610 and 1552 \\
\hline 3400 & OH & 3530.3 & OH & 3389 and 3466 \\
\hline
\end{tabular}

Table 2 Comparison between Obtained Results and Reference Results of PVATDI-SPF

\begin{tabular}{|c|c|c|c|}
\hline $\begin{array}{c}\text { Functional Group } \\
\text { Obtained }\end{array}$ & Wave number $\mathrm{cm}^{-1}$ & $\begin{array}{c}\text { Functional Group } \\
\text { Reference No.5 and } 9\end{array}$ & Wave number $\mathrm{cm}^{-1}$ \\
\hline C-H out of plane phenol & $\begin{array}{c}843.222 \text { and } \\
943.365\end{array}$ & C-H out of plane para & 826 \\
\hline C-H in plane & 1116.1 & C-H aromatic phenol & 1170 \\
\hline C-C-O phenol & 1252.06 & C-C-O phenol & 1224 \\
\hline Free Carbonyl & 1739.48 & Free Carbonyl & 1727 \\
\hline Low frequency Carbonyl & 1651.73 & Low frequency Carbonyl & 1689 \\
\hline OH & 3308.29 & OH & 3350 \\
\hline
\end{tabular}

Table 3 Samples Preparations and Dimensions

\begin{tabular}{|c|c|c|c|c|c|c|c|}
\hline $\begin{array}{c}\text { Samples } \\
\text { No. }\end{array}$ & $\begin{array}{c}\text { PVA } \\
\text { Weight } \\
\text { gm. }\end{array}$ & $\begin{array}{c}\text { TDI } \\
\text { Weight } \\
\text { gm. }\end{array}$ & $\begin{array}{c}\text { Percentages } \\
\text { SPF viscous } \\
\text { mass }\end{array}$ & $\begin{array}{c}\text { Sample } \\
\text { mength } \\
\text { mm }\end{array}$ & $\begin{array}{c}\text { Samples } \\
\text { Width } \\
\text { mm. }\end{array}$ & $\begin{array}{c}\text { Samples } \\
\text { Thickness } \\
\text { mm. }\end{array}$ & $\begin{array}{c}\text { Effective } \\
\text { Area of } \\
\text { Electrode } \\
\text { mm }\end{array}$ \\
\hline 1 & 0.06 & 0.02 & $1 \%$ & 12.2 & 5.7 & 1.8 & $1.519 \times 10^{-3}$ \\
\hline 2 & 0.06 & 0.02 & $2 \%$ & 14 & 9 & 0.9 & $1.519 \times 10^{-3}$ \\
\hline 3 & 0.06 & 0.02 & $3 \%$ & 12.06 & 6.4 & 0.875 & $5.15 \times 10^{-3}$ \\
\hline 4 & 0.06 & 0.02 & $4 \%$ & 12.2 & 5.3 & 1.9 & $4.654 \times 10^{-3}$ \\
\hline 5 & 0.06 & 0.02 & $5 \%$ & 14.2 & 7.5 & 0.9 & $4.654 \times 10^{-3}$ \\
\hline
\end{tabular}

Table 4 Dielectric Measurements and Calculations

\begin{tabular}{|c|c|c|c|c|c|c|c|c|c|}
\hline Sample No. & $\mathrm{Q}$ & $\mathrm{D}$ & $\mathrm{Rp} \mathrm{M} \Omega$ & $\mathrm{Rs} \mathrm{M} \Omega$ & $\mathrm{Z} \mathrm{M} \Omega$ & $\mathrm{Cp}$ Pf & Cs Pf & $\phi$ Deg. & $\varepsilon^{\prime}$ \\
\hline 1 & 0.689 & 1.63 & 2.276 & 1.034 & 2.075 & 66.3 & 261 & -44.4 & $3.49 \times 10^{7}$ \\
\hline 2 & 0.847 & 1.09 & 2.11 & 16.70 & 38.2 & 62.4 & 168 & -41.5 & $1.128 \times 10^{7}$ \\
\hline 3 & 0.691 & 1.71 & 1.995 & 1.355 & 1.40 & 85 & 113 & -53.2 & $2.17 \times 10^{6}$ \\
\hline 4 & 0.726 & 1.21 & 1.876 & 1.238 & 1.604 & 62.2 & 145 & -48 & $6.68 \times 10^{6}$ \\
\hline 5 & 0.931 & 1.01 & 1.695 & 1.232 & 1.182 & 90.2 & 191 & -43.3 & $8.828 \times 10^{6}$ \\
\hline \multirow{2}{*}{ Sample No. } & $\varepsilon^{\prime \prime}$ & $\mathrm{Gs} \mathrm{S}$ & $\sigma a c$ & $\sigma \mathrm{t}$ & $\sigma \mathrm{dc}$ & $\mathrm{Xs}$ & & & \\
\hline 1 & $3.68 \times 10^{7}$ & $1.06 \times 10^{-4}$ & 2.048 & 126.2 & 124 & 0.61 & & & \\
\hline 2 & $1.36 \times 10^{7}$ & $3.43 \times 10^{-5}$ & 0.755 & 20.35 & 19.6 & 0.94 & & & \\
\hline 3 & $2.04 \times 10^{6}$ & $6.64 \times 10^{-6}$ & 0.113 & 1.129 & 1.015 & 0.14 & & & \\
\hline 4 & $9.12 \times 10^{6}$ & $2.0410^{-5}$ & 0.507 & 8.336 & 7.829 & 1.09 & & & \\
\hline 5 & $9.38 \times 10^{6}$ & $2.69 \times 10^{-5}$ & 0.521 & 10.99 & 10.47 & 0.83 & & & \\
\hline
\end{tabular}




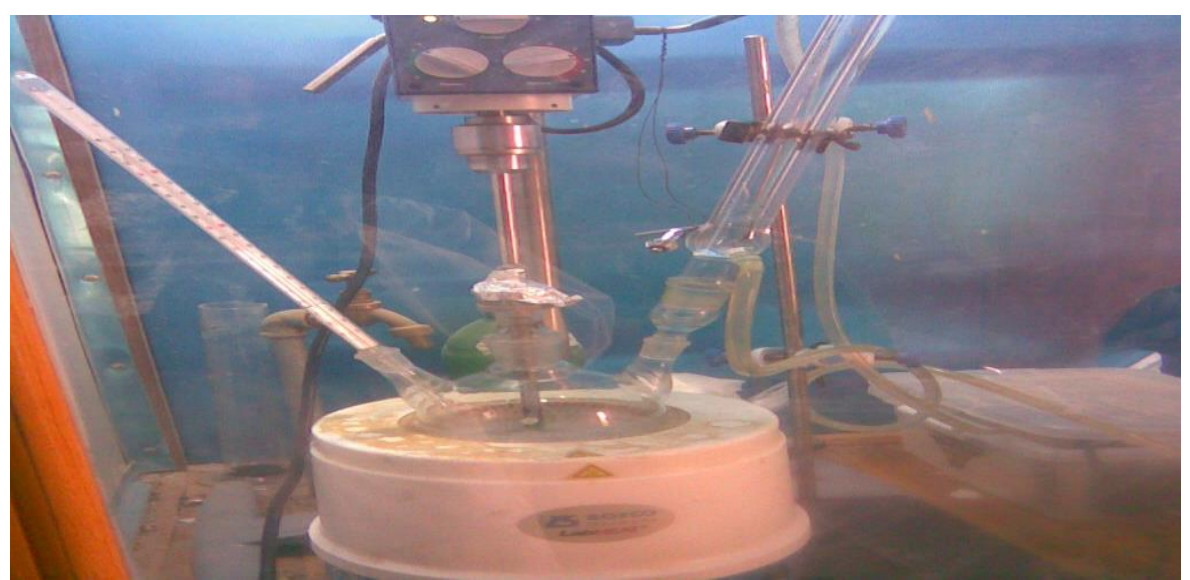

Fig.(1). The Setup of Instruments Used in Manufacture of SPF

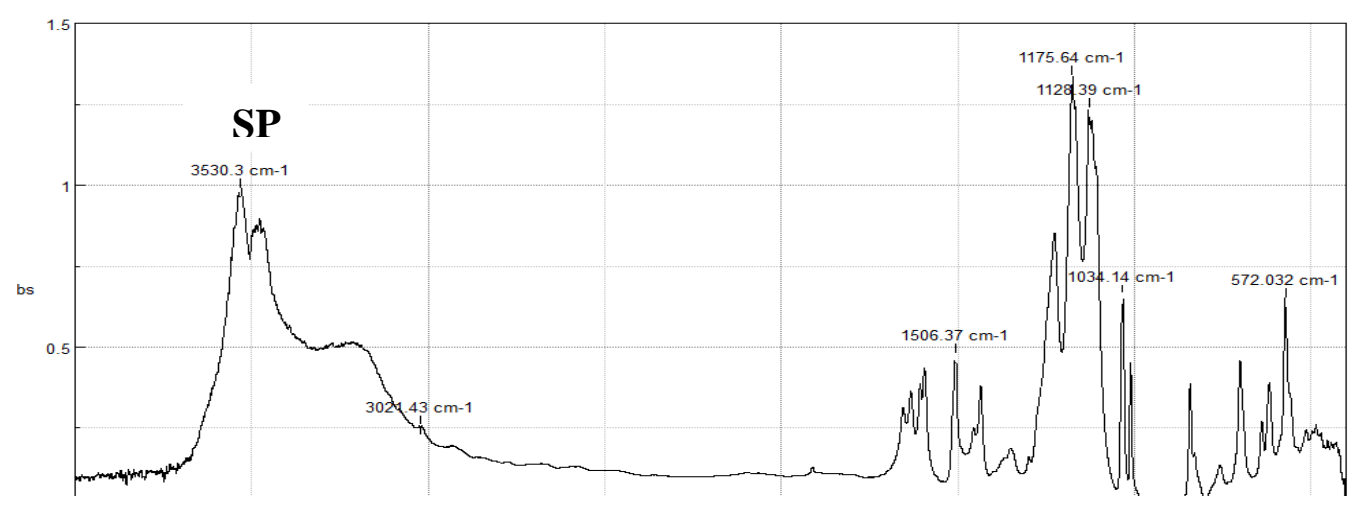

Fig.(2). The FTIR Spectroscopy of SPF.

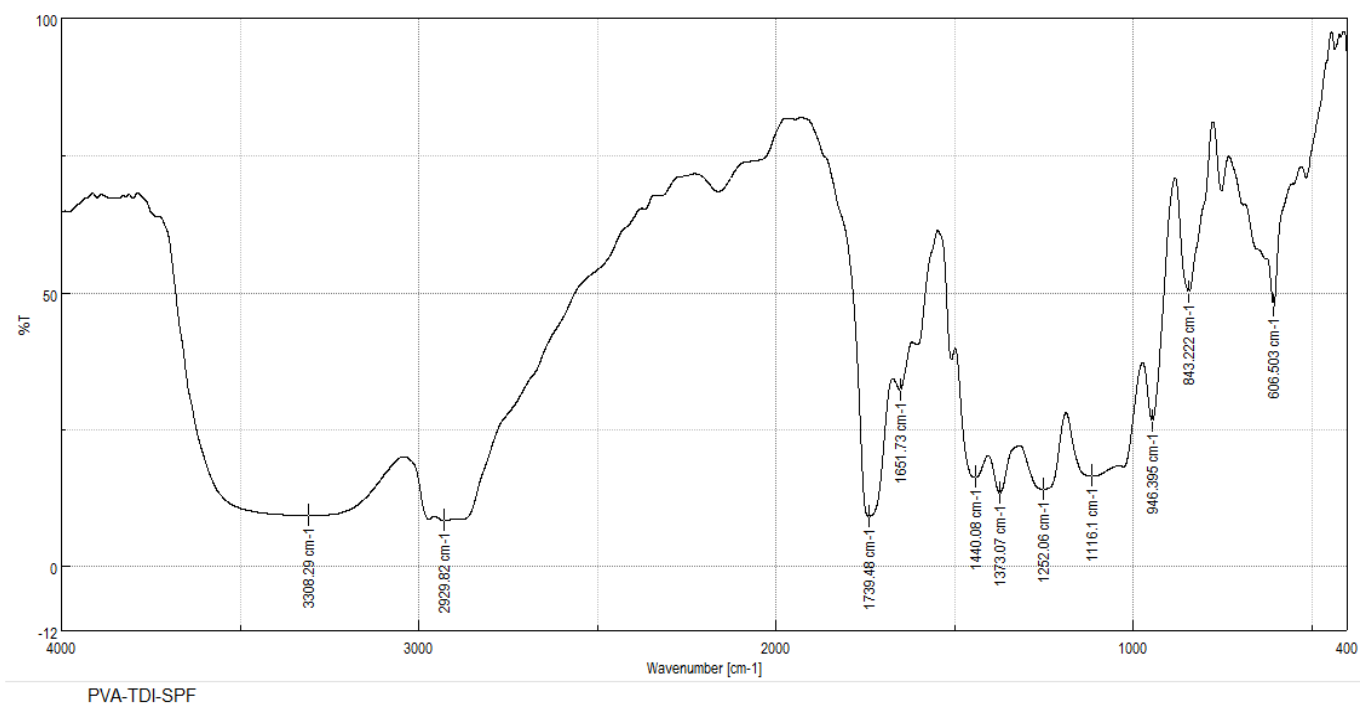

Fig.(3). FTIR Spectroscopy of PVA-TDI-SPF Mixture 


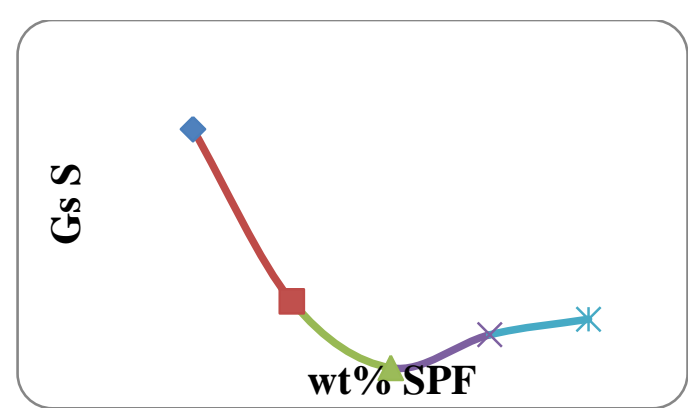

Fig.(4). Conductance Variation with wt.\% SPF
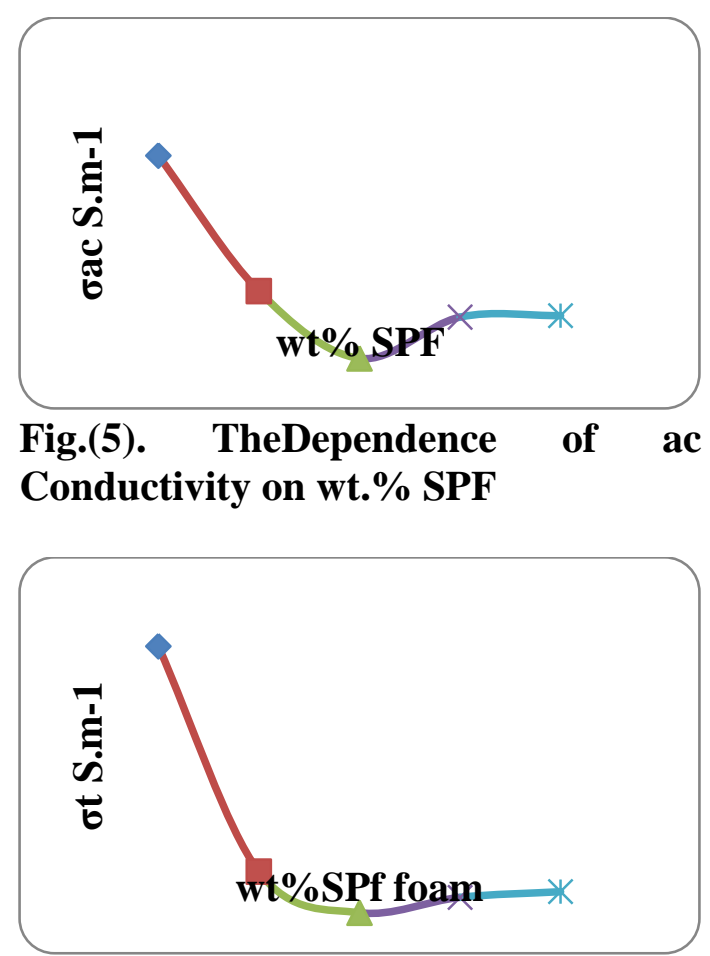

Fig.(6). The Dependence of Total Conductivity on wt.\% SPF

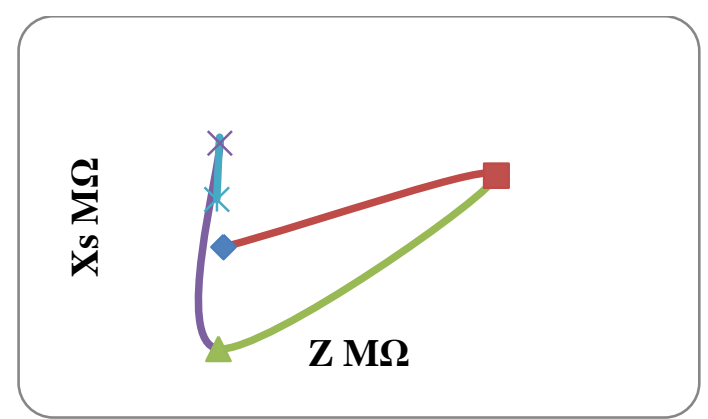

Fig.(7). Impedance vis Reactive Capacitance

FTIR spectroscopy of SPF resin is shown in Figure (2) that indicating functional groups are obtained, such as the $\mathrm{C}-\mathrm{C}-\mathrm{O}$ asymmetric and $\mathrm{C}-\mathrm{H}$ in plane formulation and out of the plane vibration. Table (1) shows the comparison between the obtained result and the results in literature. Figure (3) indicates the functional groups of PVASPF mixture and Table (2) indicates the comparison of the obtained results with previous studies, for example, the peaks at $843.222 \mathrm{~cm}^{-1}$ and $946.395 \mathrm{~cm}^{-1}$ are out of plane phenol. The peak at 1116.1 $\mathrm{cm}^{-1}$ is $\mathrm{C}-\mathrm{H}$ in plane. Table (3) indicates the samples preparations used in dielectric measurements and calculations. From Table (4), Figure (4) indicates the variation of conductance with wt.\% of SPF viscous mass to PVATDI weight, the conductance decrease with increasing wt.\% SPF viscous mass to PVA-TDI weight, the minimum decrease is at wt.3\% SPF viscous mass to PVA-TDI weight to the value $6.64 \times 10^{-6} \mathrm{~S}$, sample (3). This can be explained by a specific conductance mechanism of these materials, where even a certain number of conducting paths are present, due to the drop in voltage, more electrons are activated causing an increasing in current. [13]. The maximum value of conductance is $1.06 \times 10^{-4}$ at sample (1) wt. $1 \% \mathrm{SPF}$ viscous mass to PVA-TDI weight. Figure (5), the dependence of the frequency dependent ac conductivity $\left(\sigma_{\mathrm{ac}}\right)$ on wt.\% SPF viscous mass the maximum value of $\left(\sigma_{\mathrm{ac}}\right)$ is $2.048 \mathrm{~S} \mathrm{~m}^{-1}$ at sample (1) and the minimum value is $0.113 \mathrm{~S} \mathrm{~m}^{-1}$ at sample (3). The frequency dependent of PVA-TDI-SPF samples at $1 \mathrm{kHz}$ it is distinctly observed that the dielectric constant $\varepsilon^{\prime}$ and dielectric loss $\varepsilon^{\prime \prime}$ are decreased. Figure (6), the dependence of the total conductivity $\left(\sigma_{t}\right)$ on wt $\%$ SPF viscous mass to PVA-TDI weight. The maximum value of $\left(\sigma_{t}\right)$ is (126.2) $\mathrm{S} \mathrm{m}^{-1}$ at sample (1) and minimum value is (1.129) $\mathrm{S} \mathrm{m}^{-1}$ at sample (3). At sample (2) wt. $2 \%$ SPF viscous mass to PVATDI weight the value is (20.35) $\mathrm{S} \mathrm{m}^{-1}$. The maximum value of frequency independent dc conductivity is $124 \mathrm{~S} \mathrm{~m}^{-}$ 
1 for sample (1) and the minimum is $1.129 \mathrm{~S} \mathrm{~m}^{-1}$ for sample (3). Figure (7), the impedance vis capacitive reactance, the curve is rather alternative of the capacitive reactance with impedance of samples according to their wt\% SPF viscous mass to PVA-TDI weight. There are two major factors responsible for the contact resistance magnitude: geometry and insulating layer (potential barriers) between the contact surfaces. The resistance of the contact is inversely proportional to its area and is independent on the surface stiffness, force holding the two surfaces together. [14].

\section{Conclusions:}

The conductance of the samples shows little decrease with increasing wt.\% SPF viscous mass of PVA-TDI weight except at sample wt.3\% SPF viscous mass of PVA-TDI weight.

The frequency dependent conductivity $\left(\sigma_{\mathrm{ac}}\right)$ shows increase with increasing wt.\% SPF foam of PVA-TDI weight. The independent frequency dc conductivity $\left(\sigma_{\mathrm{dc}}\right)$ reaches the maximum values compared with the frequency dependent ac conductivity $\left(\sigma_{\mathrm{ac}}\right)$. The maximum value of total conductivity is obtained at sample wt.1\% SPF viscous mass of PVA-TDI weight to the value $126.2 \mathrm{~S} \mathrm{~m}^{-1}$.

The increase of SPF viscous mass, first conducting contact between the fibres are formed compared with composites, in this time a low conductivity at wt.3\% SPF viscous mass of PVA-TDI weight to the value $1.129 \mathrm{~S}$ $\mathrm{m}^{-1}$, this increase only slowly further, indicates only a small number of contacts between fibres in the composites at a content of several percent of SPF viscous mass.

\section{References:}

[1]Nelson, S. O. 2010. Fundamental of dielectric properties measurements and agricultural applications. Journal of Microwave Power and Electromagnetic Energy. 44(2). 98113.

[2]Velayutham, T. S.; Ahmed, A. B.; Abd Majid, W. H., and Neon, G. S. 2008. Electrical Properties of Polyurathane Graphite composites. Journal of Fizik Malaysia, Vol. 29, No. 1\&2. 25-28.

[3]Pathania, D., and Singh, D. 2009. A review on electrical properties of fiber reinforced composites. International journal of Theoritical \& applied science. 1(2): 34-37.

[4]Mohapatra, S. R.; Thakur, A. K. and Choudhary, N. P. 2008. Studies on Dielectric properties of a conducting polymer nanocomposite system. Indian Journal of Engineering \& Materials Sciences, Vol. 15. 347-351.

[5]Ali, N. A.; Mohammad N. F. T. and Hussin, S. I. 2010. Dielectric properties of industrial polymer composite material, Journal of AlNahrain University, Vol. 13 (1). 7377.

[6]Guo, L.; Wang, L. and Li, J. 2012. Study on modification of phenol formaldehyde resin adhesive with ionic liquid. $2^{\text {nd }}$ International conference on Electronic Engineering and information Technology (EMEIT).

[7]Bahargava, R.; Wang S-Q. and Koenig, J. L. 2003. FTIR Microscopy of Polymeric Systems, Adv Polym Sci, 163: 137-191.

[8]Poljansek, I. and Krajnc, M. 2005. Characterization of phenolformaldehyde prepolymer resins by line FT-IR spectroscopy. Acta ChimSlov, 52:238-244.

[9]Al-Azzawi, A. M. and Ali, M. S. 2008. Synthesis and curing of novel phenol-formaldehyde resin containing pendant citraconimides. 
Journal of Al-Nahrain University. 11(3):15-30.

[10]Barsoum, R. G. 2011. Elastomeric polymer with high rate sensitivity application in blast, shockwave and penetration mechanics, Elsevier. Edited by Rushdy George Barsoum, Plastic Design library (Pdl), R\&D Award.

[11] Aabdullah, O. Gh.; Aaziz, B. K., and Saeed, A. O. 2012. Kaolin light concentration effect on the dielectric properties of polyvinyl alcohol films. International Journal of Science and Advanced Technology, Volume 2. No. 1. 65-70.

[12]Hussien, B. 2011. The d.c and a.c electrical properties of (PMMA$\mathrm{Al}_{2} \mathrm{O}_{3}$ ) composites, European Journal of Scientific Research, 52(2):236242.

[13] Choi, E. S.; Brook, J. S.; Eaton, D. L.; Al-Haik M. S.; Hussaini,M. Y. H.; Garmestani, D. LI., and K. Dahmen, 2003. Enhancement of thermal and electrical properties of carbon nanotube polymer composite by magnetic field processing. Journal of Applied Physics, Volume 94, Number 9. 6034-6039.

[14]Long, Y-Z.; Zhaojia, C.; Zangzhi G. M. W.; Duvail, J-L.; Zongwen. L., and Ringer, S. P. 2010. A review on electronic transport properties of individual conducting polymer nanotubes and nanowires. Nanowires Science and Technology, book Editted by Nicoleta Lupu. P. 234.

\section{ايجاد العزلية الكهربائية لمكون الأسيتيت متعدد الفاينيل و تلوين داي أيسوسيانيت

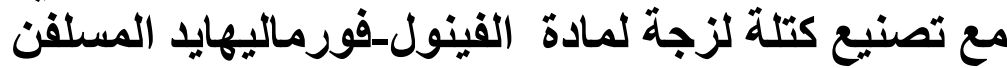

\section{أ.م ثامر سلمان بجاري}

$$
\text { مركز أبحاث البوليمر ، قسم علوم المو اد، جامعة البصرة، العراق. }
$$

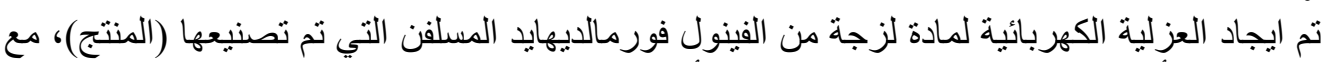

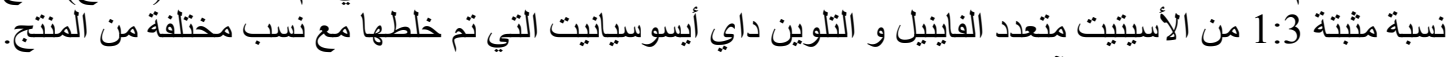

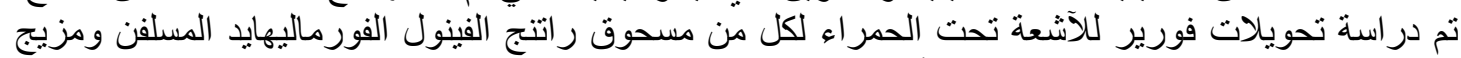

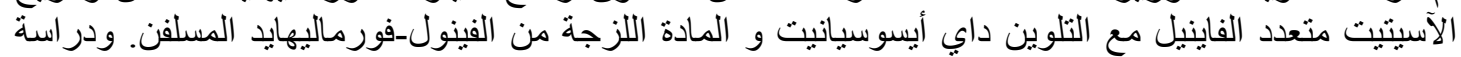

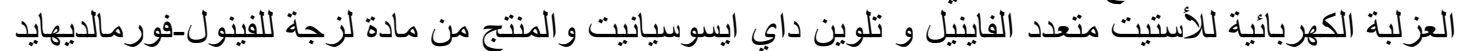

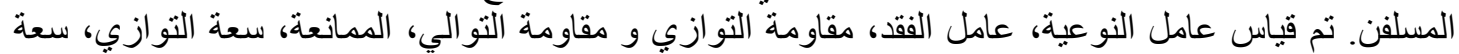

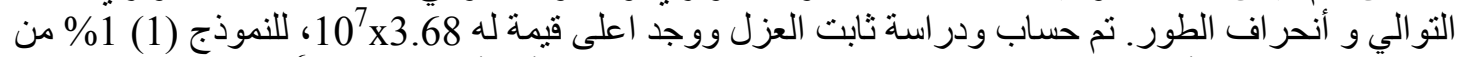

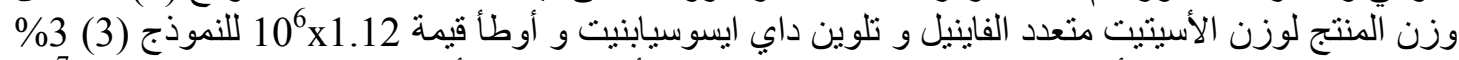

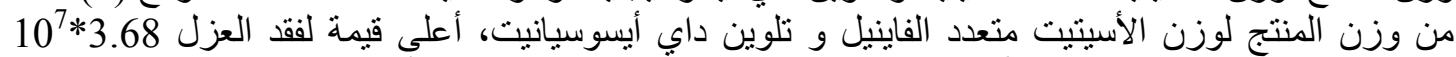

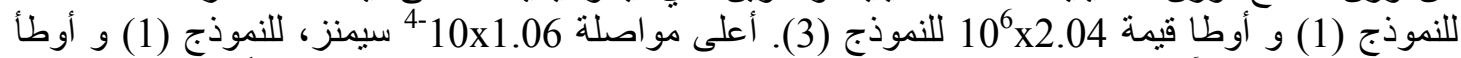

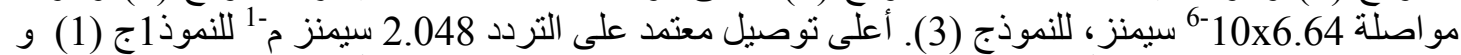

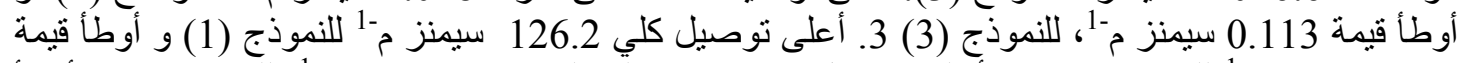

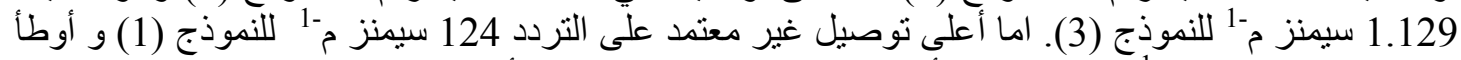

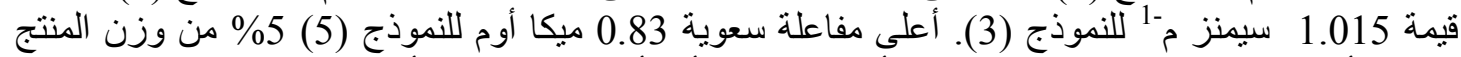

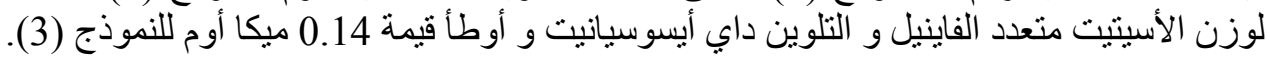

الكلمات المفتاحية: مزيج، العزل الكهربائي، التوصيل، المفاعلة السعوية 